\title{
Desde la imagen: la Biblioteca Digital Ovidiana como instrumento de estudio e investigación iconográfica del libro ilustrado ${ }^{1}$
}

\author{
Fátima Díez Platas \\ Universidad de Santiago de Compostela \\ fatima.diez@usc.es
}

Recepción: 09/04/2017, Aceptación: 06/06/2017, Publicación: 22/12/20170

\begin{abstract}
Resumen
La Biblioteca Digital Ovidiana, que se ocupa de las ediciones ilustradas de la obra de Ovidio, impresas entre los siglos XV y XIX, conservadas en las bibliotecas españolas, tiene tras de sí un proyecto de investigación cuya principal innovación consiste en la mirada específica a la ilustración. El papel de la imagen dentro del fenómeno del libro ilustrado, las relaciones que aquella desarrolla con el texto y el valor del aparato figurativo frente a la obra literaria, constituyen los principales ámbitos de análisis y estudio de las ediciones y ejemplares que el proyecto contempla. Esta contribución pretende, pues, mostrar el acercamiento a las ediciones ilustradas de Ovidio desde el trabajo que el proyecto desarrolla en relación con el análisis, el estudio y el tratamiento de las ilustraciones como imágenes y como portadoras de significado, ejemplificando las reflexiones y los procesos a través del estudio de una de las dos únicas ediciones ilustradas de las Metamorfosis españolas del siglo xvI, Las Transformaciones de Ovidio en lengua española, publicada en Amberes en 1595.
\end{abstract}

Palabras clave grabado; ediciones impresas; Ovidio ilustrado; transformaciones; Amberes; 1595

\footnotetext{
Abstract

Focusing on images: The Biblioteca Digital Ovidiana as a research tool for the study of illustrated books

The Biblioteca Digital Ovidiana is based on a research project dealing with the illustrated

1. Este artículo forma parte de los resultados del proyecto de investigación «Biblioteca Digital Ovidiana: ediciones ilustradas de Ovidio, siglos XV-XIX (IV). Las bibliotecas de la Comunidad de Madrid» (HAR2014-55617-P) financiado por el Ministerio de Economía y Competitividad.
} 
editions of the works of Ovid printed from the fifteenth to the nineteenth centuries and preserved in Spanish libraries. The main innovation of the project consists in the specific focus on illustration. The role of the image within the illustrated book, the relations that it develops with the text and the value of the figurative apparatus in relationship with the literary work constitute the main fields of analysis and study of the editions and copies. Using as a study case the Transformaciones de Ovidio en lengua castellana (Antwerp, 1595), one of the only two illustrated Spanish editions of the Metamorphoses dating from the sixteenth century, this contribution aims to show how the illustrated books are approached from the viewpoint of the figurative corpus that accompanies the text, as well as the analysis, study and treatment of the illustrations as images, that is, as bearers and conveyors of specific meaning through a different medium.

\section{Keywords}

engravings; printed editions; Ovid illustrated; Transformaciones; Antwerp; 1595

Fortius irritant animos quae picta leguntur

Así reza el motto que enmarca la imagen de un libro abierto en el que se aprecia de manera clara la página de texto enfrentada a la que va adornada con un grabado, en una vińeta concebida a modo de divisa que aparece entre los elementos decorativos de una edición con la traducción al alemán de los siete primeros libros de las Metamorfosis de Ovidio (figura 1). ${ }^{2}$ Esta lapidaria afirmación, que se podría traducir como «las cosas que se leen pintadas —o lo que se lee ilustrado- excitan más la mente o la imaginación», llama la atención sobre el valor de la imagen en el contexto del libro, actuando de manera efectiva como metarreferencia dentro de una edición excepcionalmente ilustrada que contiene uno de los textos que, junto con la Biblia, se han ilustrado más profusamente a lo largo del tiempo.

2. P. Ovidii Nasonis Metamorphosis Oder Sinn-reicher Gedichte von Verwandlungen (...), Núremberg, 1698. Una copia digitalizada de la edición se puede consultar en la base de datos iconográfica del Instituto Warburg de Londres (<http://iconographic.warburg.sas.ac.uk/vpc/VPC_search/ main_page.php>). 


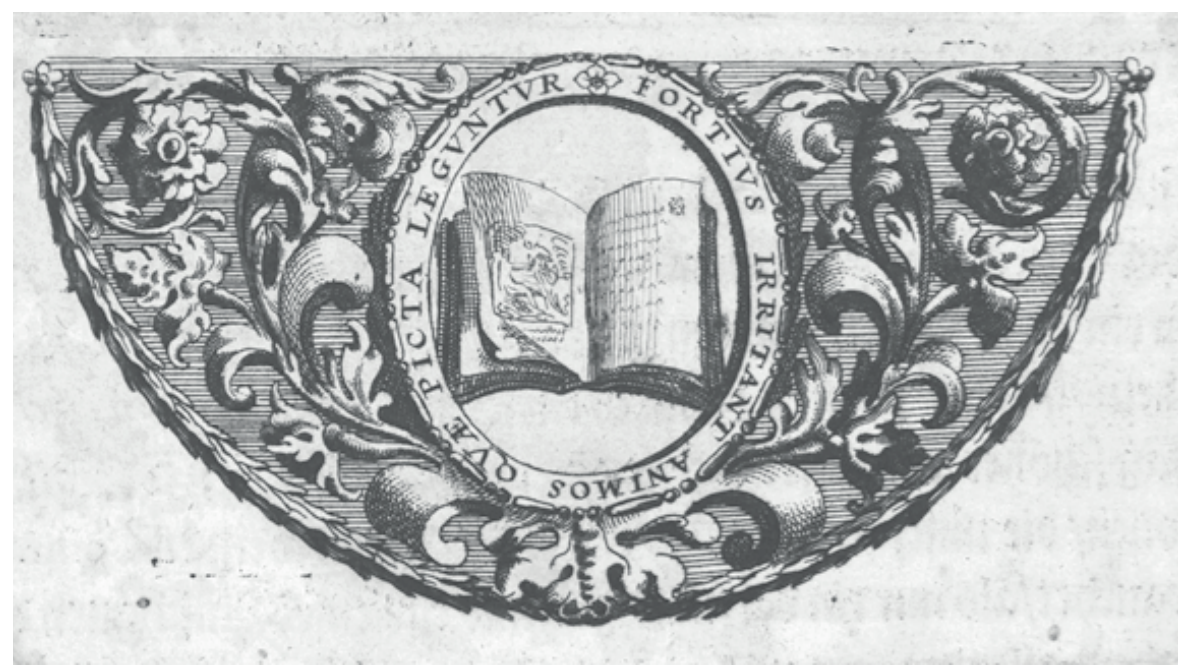

Figura 1.

Viñeta de la edición alemana P. Ovidii Nasonis Metamorphosis Oder Sinn-reicher Gedichte von Verwandlungen, Núremberg, 1698, p. 12.

Biblioteca privada, A Coruña.

El valor del libro ilustrado, sin embargo, no se agota en esta virtud de excitar la imaginación, porque la imagen no solo desarrolla el cometido primordial de materializar el sentido literal del término «imaginar», promoviendo la visualización de los contenidos textuales, sino que, en la tarea de percibir el texto y sus contenidos, sirve de complemento tanto decorativo como significativo, ya que actúa amplificando la información textual con los medios propios de que dispone el medio visual.

La adición de un aparato figurativo a una obra literaria con frecuencia sirve para conectar dos medios, el textual y el visual, poniendo a prueba las capacidades propias de cada uno de ellos en la tarea de conferir significado, que quizá sea necesario entender como una empresa conjunta en la que ambos medios se complementan. Sin embargo, es evidente que de maneral general el medio textual es preponderante, es decir, se sitúa por encima en la tarea, lleva «la voz cantante», porque, en el caso de la ilustración de las obras literarias, en principio, el contenido textual es el origen del que va a partir la creación figurada, a la cual se va a imponer la labor subsidiaria de ilustrar y, por tanto, de supeditarse en el campo de los contenidos a la creación literaria. Esta relación, no obstante, se puede llegar a invertir sin perder del todo la presencia de la obra-origen, como se puede ver, de manera concreta, en las versiones ilustradas de algunos textos, que se reducen a imágenes acompañadas por mínimos apoyos textuales. Este es el caso de varias ediciones de las Metamorfosis, que sufrirán — como si el título del poema obrase una suerte de maldición o imperativo ineludible- se- 
veras transformaciones que alterarán por completo la pieza original del poeta de Sulmona, sin que por ello pierdan su reconocible personalidad. ${ }^{3}$

De manera general, el libro ilustrado es generalmente considerado «un libro bonito", es decir, una pieza que gana en vistosidad y en valor en relación con el libro que solo cuenta con aspectos como el cuidado y la belleza de la composición o la tipografía para despertar la admiración estética.

No obstante, el papel de la ilustración dentro del estudio del libro y las ediciones se considera como un aspecto más que es necesario reseñar en la descripción del contenido de la publicación, una condición que simplemente puede o no estar presente. De este modo, en relación con la ciencia biblográfica o biblioteconómica se debe perfilar aún más el espacio para resaltar o poner en su justo lugar el valor del aparato figurativo de una edición, más alla de la cuestiones marginales de la decoración o el ornato, para poder considerarlo también desde el punto de vista del significado y la relación con el texto. ${ }^{4}$

Este valor significativo de la ilustración dentro del libro, tiene un importante aspecto relacionado con el receptor o destinatario, ya que, más allá de la pura información que la imagen puede aportar, especialmente en obras que nacen destinadas a apoyarse en un dispositivo visual para completar la información y el sentido de la obra, el libro ilustrado propone y supone un acercamiento distinto a los contenidos. El concurso del texto y de la figuración permite comprender de dos maneras aspectos narrativos o poéticos, y, sobre todo, permite establecer conexiones que van más alla de la mera comprensión del contenido o la significación de las palabras, porque facilitan el ejercicio de relacionar maneras de decir con modos de representar. Así, sin duda, ponen a

3. Se puede considerar que el primer caso de este tipo de ediciones lo constituye La Métamorphose d'Ovide figurée, publicada en Lyon por Jean de Tournes en 1557, que supone una transformación radical del texto ovidiano en relación con la imagen. Estructurada de manera similar a un libro de emblemas, la singular edición del poema de Ovidio se compone de 178 xilografías realizadas por el famoso grabador lionés Bernard Salomon, que van acompañadas por un título y un epigrama que se limita a glosar brevemente en francés el contenido de la imagen. Sobre el grabador lionés véase la edición de B. Salomon y su ilustración, véase Henkel (1926-1927: 77-81) y sobre la relación con el resto de la tradición figurada de Ovidio en el xvi, véase Díez Platas y Meilán Jácome (2016: 279-280). Una digitalización de la edición puede verse en <http://ovid.lib.virginia.edu/ salomonsimeoni.html>.

4. Los estudios sobre emblemática, por la propia naturaleza de los libros de Emblemas son pioneros en el tratamiento y la consideración del papel de la imagen en relación con el texto. A este respecto es necesario aludir al Emblem Project Utrecht (<http://emblems.let.uu.nl/>) y especialmente al del Centre for Emblems Studies de la Universidad de Glasgow (<http://www.emblems.arts.gla. ac.uk/>). En relación intrínseca con esas iniciativas se encuentra la labor realizada en relación con la Literatura, la Historia, la Historia del libro y bibliotecas y la Historia del Arte de los siglos XVI y XVII, un paradigmático e impecable quehacer investigador, recogido y resumido en BIDISO: Biblioteca Digital del Siglo de Oro, que procede de la iniciativa y desarrollo de la profesora de la Universidade de A Coruña, Sagrario López Poza: <http://www.bidiso.es/index.htm;jsessionid=10EF33E2008DF0BF4C3705B9254498E1 >. Sobre el desarrollo de este campo de estudio y el desarrollo reciente de la biblioiconografía, véase Férnandez Valladares (2012). 
prueba la capacidad de imaginar —en las dos acepciones — no solo del ilustrador, sino sobre todo del lector o receptor, que aprecia con frecuencia las connotaciones o las amplificaciones del sentido por medio de su transformación en expresiones de tipo visual. Y por encima de todo ello - y esto es en parte el objetivo de esta contribución-, se encuentra una especie de metarreflexión: el libro ilustrado proporciona la oportunidad de pensar e indagar sobre el quehacer artístico, sobre el valor intrínseco de la imagen, sobre la variación de la visión estética de cada momento y sobre la posibilidad de establecer conexiones de estilo entre los medios. Unas conexiones que, a veces, se perciben como ejercicios de divergencia, o, por el contrario, como necesarias pistas para una correcta contextualización.

Para poder comprender estos valores que la adición de la imagen proporciona al libro, se hace necesario habilitar una herramienta de estudio de la ilustración en el medio librario. Y entre las cuestiones que implica este estudio no solo se cuentan cosas evidentes, como conocer el artífice y el procedimiento de incorporación de las imágenes al libro, sino, sobre todo, se impone poder indagar el porqué de la incorporación de la imagen para ponerla en relación con el texto, el desarrollo y los antecedentes del proceso, y el sentido y la envergadura de esta relación en términos cualitativos y cuantitativos. Y, de manera especial, para comprender el fenómeno de la ilustración, resulta interesante indagar en la relación que desarrolla el texto con la imagen desde el punto de vista del contenido, es decir, si estamos frente a una ilustración en el sentido estricto, que vierte de manera equiparable la información del texto en una imagen, o si aporta otro tipo de información que, de algún modo, está vedada para el texto como medio. Por último, resulta evidente el interés que despierta, saltando al plano de la consideración del propio libro como imagen, el papel y la posición de la imagen en relación con el texto en la composición y presentación de la página, y el sentido que esto tiene para comprender ambas cosas, el valor de la imagen y el valor del texto.

\section{La Biblioteca Digital Ovidiana: un proyecto sobre la obra ilustrada de Ovidio}

Para afrontar algunas de estas cuestiones en relación con un conjunto definido, concreto y privilegiado de libros ilustrados en el marco de las Humanidades Digitales se ha concebido la Biblioteca Digital Ovidiana (a partir de ahora $B D O$ ), un proyecto de investigación sobre la obra del poeta romano y la edición impresa que la ha divulgado con ilustraciones desde el siglo Xv al siglo XIX. Una iniciativa que intenta contemplar las versiones ilustradas de la producción ovidiana atendiendo a los problemas y cuestiones que plantea esta «mirada doble», al texto y a la imagen, pero que parte de una tarea de recopilación y estudio, ya que es un proyecto de corte principalmente patrimonial, que aspira a contener en su sitio web todos los ejemplares de las ediciones 
ilustradas de las obras de Ovidio impresas entre los siglos XV y XIX que se encuentran en las bibliotecas espańolas. ${ }^{5}$

De manera general, el proyecto pretende contemplar todos los ejemplares de las ediciones ilustradas, y este intento de recopilación exhaustiva de ejemplares y no sencillamente la búsqueda y estudio de las ediciones, tiene un sentido especial en la intención de hacer una recuperación patrimonial de la obra ilustrada de Ovidio en España, para rescatar piezas desconocidas, identificar ejemplares mutilados o dañados que han perdido sus características definitorias, como la portada, colofón o las informaciones clave para la identificación de la edición. Este deseo de revisar todos y cada uno de los ejemplares se imbrica además en la línea renovada de la Historia material del libro, que conciencia sobre la importancia de la vida de los ejemplares que hablan de sus poseedores, que proporciona datos sobre la lectura de la literatura clásica, y del interés en las bibliotecas espańolas y los lectores por un autor como Ovidio, contemplado a través de la presencia de libros especiales, ornados, de cuidada edición o especialmente valiosos por la adición de imágenes, hecho que los convierte en obras de arte, con frecuencia alteradas o enriquececidas por decisión del poseedor.

Las tareas que desarrolla el proyecto de investigación consisten, en primer lugar, en individualizar los ejemplares ilustrados después de haber revisado físicamente los fondos ovidianos de cada biblioteca. A través de los ejemplares localizados se estudian las características de la edición y de cada una de las copias. En relación con el aparato figurativo, se fotografían o digitalizan las portadas y todas las ilustraciones, que es lo que va a constituir uno de los objetivos primordiales del estudio.

Concluido el trabajo en la biblioteca, los datos se vierten en unas fichas específicamente diseñadas para contener información bibliográfica del ejemplar, que implican la descripción de la edición y las peculiaridades del volumen.

5. La $B D O$ es un proyecto en desarrollo que, desde su comienzo en 2007 , se ha concebido en fases. En este momento ya ha completado sus tareas en casi la mitad del territorio nacional: fase I (2007- 2010): «Biblioteca Digital Ovidiana: ediciones ilustradas de Ovidio, siglos Xv-XIX (I): las bibliotecas de Galicia y Cataluña» (HUM2007- 60265/ARTE); fase II (2011-2012): «Biblioteca Digital Ovidiana: ediciones ilustradas de Ovidio, siglos XV-XIX (II): las bibliotecas de Cataluña» (HAR2010-20015); fase III (2012-2014): «Biblioteca Digital Ovidiana: ediciones ilustradas de Ovidio, siglos Xv-XIX (III): las bibliotecas de Castilla y León» (HAR2011-25853), y fase IV (2015-2017): «Biblioteca Digital Ovidiana: ediciones ilustradas de Ovidio, siglos XV-XIX (IV): las bibliotecas de la Comunidad de Madrid» (HAR2014-55617-P). 


\begin{tabular}{|c|c|}
\hline Portada y título & $\begin{array}{l}\text { El título completo tal y como figura en la obra, } \\
\text { acompañado de la imagen de la portada del ejemplar } \\
\text { si la conserva }\end{array}$ \\
\hline Obra & Cada una de las obras contenidas en el ejemplar \\
\hline Lugar de publicación & $\begin{array}{l}\text { La ciudad con su nombre completo como figura en la } \\
\text { edición y en latín, en locativo. }\end{array}$ \\
\hline Impresor & $\begin{array}{l}\text { Nombre del impresor con su enlace a la base de datos } \\
\text { del Consortium of European Research Libraries }\end{array}$ \\
\hline Comitente & Nombre de la persona que costea o encarga la edición \\
\hline Ilustrador & $\begin{array}{l}\text { Nombre del ilustrador con su enlace a la base de datos } \\
\text { del Consortium of European Research Libraries }\end{array}$ \\
\hline Fecha & Fecha del ejemplar \\
\hline Biblioteca & Ubicación del ejemplar \\
\hline Signatura & Código de identificación del ejemplar en la biblioteca \\
\hline $\begin{array}{l}\text { Características de la } \\
\text { edición }\end{array}$ & $\begin{array}{l}\text { Un menú desplegable que contiene los datos de la } \\
\text { edición: } \\
\text { - El texto y/o traducción } \\
\text { - Los comentarios y adiciones al texto ovidiano } \\
\text { - Tipo de ilustración } \\
\text { - Estructura y disposición de la página } \\
\text { - Bibliografía }\end{array}$ \\
\hline Contenido & $\begin{array}{l}\text { Desglose del contenido de la edición con la indicación } \\
\text { de los folios o páginas donde se comienza cada una de } \\
\text { las partes }\end{array}$ \\
\hline $\begin{array}{l}\text { Características del } \\
\text { ejemplar }\end{array}$ & $\begin{array}{l}\text { - Un menú desplegable que contiene los datos } \\
\text { principales de cada ejemplar concreto:Historial: } \\
\text { historia de los poseedores del ejemplar } \\
\text { - Descripción física: información técnica del } \\
\text { ejemplar con todos los datos bibliográficos } \\
\text { - Referencias: reseña de su catalogación } \\
\text { - Observaciones: datos relevantes sobre la } \\
\text { conservación del ejemplar }\end{array}$ \\
\hline Lista de ilustraciones & $\begin{array}{l}\text { Contiene la enumeración, posición y descripción } \\
\text { temática de todas y cada una de las ilustraciones, con } \\
\text { observaciones sobre la conservación y alteración de los } \\
\text { grabados. Va acompañada de la galería de } \\
\text { ilustraciones, con todas las imágenes de todas las } \\
\text { ilustraciones del ejemplar, que aparecen como una } \\
\text { página de contactos desde la que se accede a cada } \\
\text { uno de los grabados y a su información }\end{array}$ \\
\hline $\begin{array}{l}\text { Ejemplares bibliotecas } \\
\text { españolas }\end{array}$ & $\begin{array}{l}\text { Noticia de los ejemplares iguales que se conservan en } \\
\text { las bibliotecas españolas }\end{array}$ \\
\hline
\end{tabular}

Figura 2.

Ficha bibliográfico-iconográfica. Biblioteca Digital Ovidiana.

En las ficha bibliográfico-iconográfica se incluye también la detallada relación del aparato figurativo con la descripción, identificación y análisis material de cada una de las ilustraciones de distinto tipo que incluye cada edición y se manifiesta en cada ejemplar, reseñando las alteraciones, pérdidas y adiciones. La información completa incluida en la ficha, que constituye un verdadero estudio de cada uno de los ejemplares e implica el conocimiento de la edición a la que cada copia representa, se trata a continuación de diversas formas para convertirla en datos informáticos que permitirán la visualización de cada ejemplar dentro de la propia biblioteca digital. ${ }^{6}$

La base de datos diseñada contiene, pues, un reflejo de esta ficha bibliográficoiconográfica creada ex profeso para reflejar la información necesaria y pertinente sobre cada uno de los especímenes estudiados y digitalizados. El modelado de los datos que se han jerarquizado de manera precisa para su introducción en la ficha ha pro-

6. Alojada en <www.ovidiuspictus.es> (también <www.ovidiuspictus.net>, y <www.ovidiuspictus.eu>). 
piciado la creación de un sistema de identificación de ediciones y ejemplares, único y pertinente, que se traduce en la creación de dos tipos de código: uno para la edición y otro para el ejemplar concreto que se localiza en una determinada biblioteca. Ambos códigos facilitan la organización de la base de datos y de los materiales en el proceso de estudio. Así, para cada una de las ediciones de la obra ilustrada de Ovidio se ha creado un código de nominación que permite reconocer de manera inmediata la edición de la que se trata. El código se compone de la obra, seguida del nombre del editor, traductor o comentarista de la abreviatura de la obra (si se trata de una edición comentada o traducida), a continuación el nombre del impresor, el lugar de impresión y la fecha. De este modo, el código Metamorfosis/M.Bustamante.Bellero. Amberes. 1595 corresponde a la traducción de las Metamorfosis realizada por Jorge de Bustamante y editada por Pedro Bellero en Amberes en 1595. El código del ejemplar, por su parte, es una descripción abreviada de la edición, el ejemplar y la biblioteca que lo posee, de modo que se reseńa en abreviatura la obra, el acrónimo de la biblioteca, el lugar de publicación y el año. Así, el código M.BXU.Amb.1595 se corresponde con el ejemplar de la mencionada traducción que se encuentra en la Biblioteca Xeral de la Universidad de Santiago de Compostela. ${ }^{7}$ De esta manera aparecen listadas las ediciones y los ejemplares en el sitio Web, lo que facilita una rápida identificación de las obras, las ediciones y los ejemplares dentro de las bibliotecas que los poseen. ${ }^{8}$

\section{Museo de libros o biblioteca de imágenes: la $B D O$ y los libros ilustrados en el mundo virtual}

De manera concreta, el conocimiento de la edición de las obras del poeta romano que se deriva del trabajo intensivo de revisión de cada ejemplar en cada biblioteca visitada, lleva aparejado el conocimiento de las ilustraciones y, por tanto, del desarrollo del torrente de imágenes que ha producido el intento de acompañar con figuración los textos ovidianos, especialmente, el poema de las Metamorfosis, durante los siglos contemplados por el proyecto. La propia recopilación que hace Ovidio en su poema produce una transformación de los episodios mitológicos que se ve exponencialmente amplificada por la generación de versiones visuales, y por la constatación de que la imagen opera una nueva y especial transformación de los contenidos poéticos. Las historias del poema se convierten en escenas y motivos, acuñados por el tiempo y por los intentos de representación, que alcanzan cotas insospechadas de pertinencia y se instalan en las mentes de los artistas y de los lectores.

7. Dada la exigua información que se proporciona en el código del ejemplar se pueden producir raros casos de coincidencia entre los ejemplares de ediciones diferentes pero editadas en el mismo lugar y en la misma fecha. Para ello se han establecido sencillos métodos de desambiguación que consisten en la adición de dígitos o letras que marcan las diferencias. En este momento, están ya contempladas y subsanadas todas las posibles ambigüedades.

8. Lista de ediciones de la $B D O:<$ http://www.ovidiuspictus.es/listadoediciones.php>. 
Por este motivo, el tratamiento de las imágenes de las obras ilustradas de Ovidio en la $B D O$ es detallado, no solo en la definición técnica, en la descripción física, o en el recuento y enumeración de las ilustraciones de cada edición, sino sobre todo en el análisis y la identificación de los temas de los episiodios representados, que completa la visualización individual y en conjunto de cada grabado y de la serie que constituye el programa figurativo de cada edición.

Esta mirada específica y comprensiva de la imagen, gracias a la transformación digital, resulta en la posibilidad de acceder al aparato figurativo de manera integral, esto es, poder visualizar en conjunto - y de manera prácticamente simultánea- todas las ilustraciones de una edición. Algo que no es ni nuevo ni privativo de la $B D O,{ }^{9}$ pero que facilita de manera extraordinaria la comprensión del valor de las imágenes dentro del libro e invita a la reflexión. Esta presentación, por una parte, se convierte en un dispositivo de búsqueda temática más rápido y basado en la percepción visual, mientras que, por otra, muestra las relaciones entre las imágenes y la envergadura de la ilustración de cada edición prácticamente en un golpe de vista.

En el marco del proyecto, el estudio de las relaciones de la imagen con los textos en las obras de Ovidio se constituye, por su parte, en un tema de importancia capital por la propia naturaleza visual de las ediciones de las Metamorfosis, aunque el resto de las obras de Ovidio, de una manera desigual, también han merecido distintos tipos de ilustración y aparatos visuales para resaltar aspectos diversos de la creación del poeta. Las Metamorfosis editadas en Europa desde el final del siglo xv han desarrollado un carácter de manual o pequeña enciclopedia de temas y motivos poéticos — piénsese en la edición del primer incunable ilustrado de la obra en traducción francesa que imprime A. Verard en París en 1493, por primera vez bajo el título de la Bible des Poètes—, pero sobre todo de inspiración artística, como lo prueba la difusión de las creaciones producidas para la ilustración del texto que han acabado en los lienzos de los mejores pintores europeos de la época moderna. Este carácter de reservorio de ideas artísticas y de soluciones iconográficas que tienen las ilustraciones de las ediciones de las Metamorfosis, ha contribuido de manera especial a cambiar el valor de las ediciones del poema con grabados, pero, sobre todo, ha ayudado a difundir por una vía adicional las historias y los episodios concebidos por Ovidio, que han influido en la literatura de casi todos los siglos posteriores a la muerte del poeta.

Por esta razón, el conocimiento y la difusión visual de las ilustraciones constituyen en sí mismos unos motivos poderosos para modificar el acercamiento al

9. Este tipo de presentación constituye no solo la base de las simples presentaciones en galería u hoja de contactos de las páginas de buscadores de imágenes como Google imágenes, por ejemplo, pero resulta especialmente significativo y operativo en la propuesta del magnífico proyecto sobre libros de emblemas de la universidad de Glasgow, que desde el principio sirvió de inspiración para realizar un planteamiento similar en la BDO. Una muestra de este tipo de presentación de los contenidos iconográficos del libro es posible de encontrar en: <http://www.emblems.arts.gla.ac.uk/alciato/contents.php?id=A31a> . 


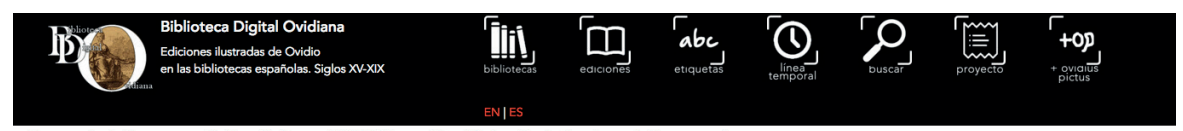

Metamorfosis.Bustamante.Bellero.Amberes.1595 Biblioteca Xeral Universitaria. Santiago de Compostela.

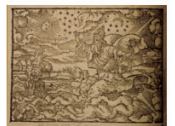

Libro 1 (f. 1v).

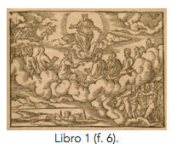

Libro $1(f .6)$.

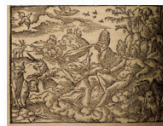

Libro 1 (f. 2v).

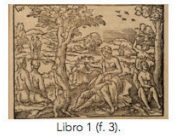

Libro 1 (f. 3).

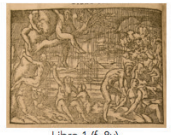

Libro 1 (f. Bu).

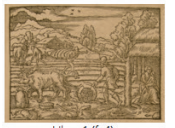

Libro 1 (f. 4).

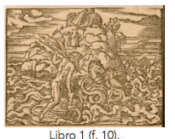

Libro 1 (t. 10).

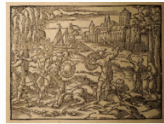

Libro 1 (f. .4v).
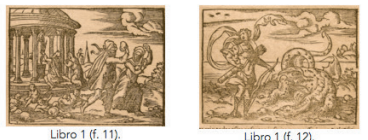

Figura 3.

Detalle de la galería de imágenes de Biblioteca Digital Ovidiana de la edición Metamorfosis.Bustamante.Bellero.Amberes.1595 (ejemplar de la Biblioteca Xeral de la Universidad de Santiago de Compostela: M.BXU.Amb.1595).

libro ilustrado y la utilización de las herramientas virtuales para producir una nueva metamorfosis del libro. Como ya he expuesto en otra ocasión (Díez-Platas 2016: 29-32), la visualización de las ilustraciones y su consideración de manera individual convierten a la $B D O$ en una biblioteca especial, que es, a la vez, una suerte de «museo virtual» en el que se pueden contemplar las imágenes por sí mismas, tal y como se perciben a través de la labor de los artistas que las utilizaron para crear propuestas similares en diferentes medios.

Pero no se trata de difundir sencillamente grabados o ilustraciones como imágenes sueltas y separadas de su continente, porque el momentáneo «museo virtual» en que se convierte la galería de imágenes de un ejemplar de la $B D O$ no se desliga nunca de su contenedor: el libro. Este articula y organiza el programa iconográfico y da sentido a las relaciones entre las propias ilustraciones. Por otra parte, al mantenerse ligadas al libro, mostrando su posición en relación al texto y su relación con los contenidos literarios, las imágenes no solo están contextualizadas, sino sobre todo explicadas, porque para darles sentido cuentan con la información del texto, pero sobre todo con la del libro. Indudablemente, aunque unas líneas más arriba se ha afirmado la autonomía de la imagen en la percepción de los creadores, sin duda hay que admitir, que también de esta manera «textualizada» o, quizá mejor aún «libresca» fueron comprendidas por los artistas, que aprovecharon no solamente la información visual o iconográfica, sino en muchos casos se sirvieron del complemento del libro para repensar las creaciones. ${ }^{10}$

10. Un ejemplo paradigmático es el uso de las ediciones ovidianas que hizo Pedro Pablo Rubens para la realización del programa pictórico de la Torre de la Parada en Madrid (Alpers 1971). 
De este modo, el acceso al libro ilustrado a través de los medios digitales que nos permite leer el texto, ${ }^{11}$ conocer su realidad editorial, su historia material y su equipaje figurado produce el efecto de poder visitar la biblioteca y el museo de manera simultánea, una suerte de visión integral mejorada para aprehender significados de manera más efectiva.

\section{Un estudio visual: Las Transformaciones de Ovidio en lengua española (Amberes, 1595) en la BDO}

El planteamiento de la $B D O$ como herramienta para la investigación se puede mostrar de manera detallada a través del estudio y tratamiento realizado con una edición ilustrada de la obra de Ovidio que constituye un caso especial para explorar varios aspectos en relación con el libro ilustrado, la difusión de la obra ovidiana y el valor iconográfico de la utilización de la imagen.

La obra en cuestión es la edición publicada en Amberes en 1595 por el impresor Pedro Bellero, que lleva por título Las Transformaciones de Ovidio en lengua española, repartidas en quince libros, con las Allegorias al fin dellos, sus figuras, para provecho de los Artífices (figura 4). Se considera la décimosegunda edición de la primera traducción española del poema ovidiano en el siglo Xvi, que es una versión moralizada en prosa y se atribuye a Jorge de Bustamante. La obra tuvo un enorme éxito, de modo que se convirtió en la traducción al español más difundida durante todo el siglo, y se reeditó todavía cinco veces más durante el siglo XVII y una última en el siglo XVIII. De las 18 ediciones, la de 1595 es la única que va ilustrada. ${ }^{12}$

En las bibliotecas españolas se conservan doce ejemplares de esta edición, cuatro de ellos en la Biblioteca Nacional. ${ }^{13}$ Hasta este momento, hemos consultado y estudiado ocho y ya están disponibles en el sitio Web las fichas y estudios

11. En el caso de la $B D O$ la relación de la imagen no está contemplada de manera efectiva, porque no se digitaliza el libro completo. En cualquier caso, la posibilidad de establecer la relación de una determinada imagen con el texto al que acompaña, o con el texto original de la obra ovidiana, se propicia al facilitar la posición de la imagen en el libro, la parte del contenido (libro, canto, etc.) en la que se encuentra incluida y, de manera evidente, a través de la identificación del tema. En los casos en los que están disponibles en la ficha de cada ejemplar se proporciona un enlace a la copia digitalizada.

12. Sobre la traducción de Bustamante y sus ediciones, véase Carrasco Reija (1997).

13. Los ejemplares conservados son los siguientes: Córdoba, Montilla, Fundación Manuel Ruiz Luque (Ayuntamiento de Montilla), sign.: C.2.b./071; Sevilla, Biblioteca Capitular y Colombina, sign.: Capitular, 18-1-33; Gerona, Ripoll, Biblioteca Pública Lambert Mata, sign.: R-10; Madrid, Biblioteca Nacional, sign.: R/25206; CERV.SEDÓ/8736; R/8723 (Digitalizada en BDH: <http://bdh-rd.bne.es/viewer.vm?id=0000187259\&page=1>), y R/8927; Madrid, Fundación Lázaro Galdiano, sign.: Inv. 2207; Madrid, Museo del Prado, Biblioteca, sign.: Cerv/173; Madrid, Real Academia de Ciencias Morales y Políticas, sign.: 18078; Madrid, Universidad Complutense, sign.: BH FLL30833. (Digitalizada: <http://alfama.sim.ucm.es/dioscorides/consulta_libro. asp?ref=B20978182>); La Rioja, Biblioteca privada. 


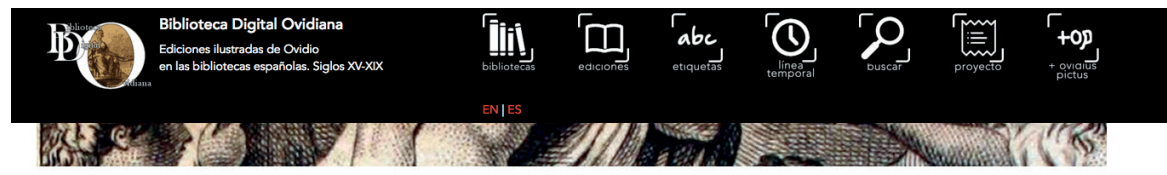

Biblioteca Xeral Universitaria. Santiago de Compostela >Metamorfosis. Bustamante. Bellero.Amberes.1595
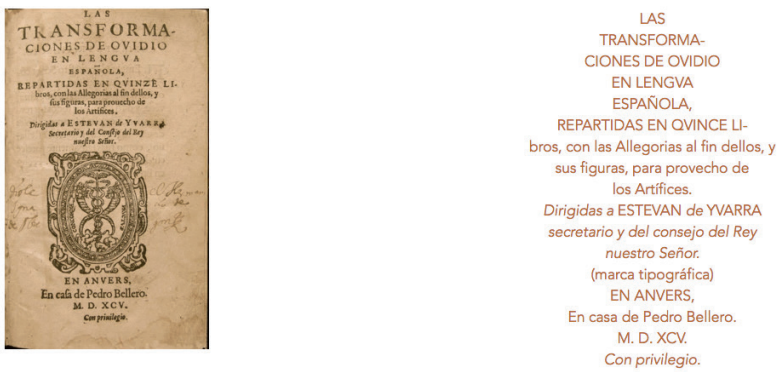

Figura 4.

Detalle de la portada y título de la edición Metamorfosis.Bustamante.Bellero. Amberes.1595 en la BDO (ejemplar del Museo del Prado, Madrid: M.MP.

Amb.1595).

de cuatro: los ejemplares de la Biblioteca Xeral de Santiago de Compostela, el ejemplar de la Biblioteca Histórica Marqués de Valdecilla, de la Universidad Complutense de Madrid, el de la biblioteca del Museo del Prado, y el de la biblioteca de la Real Academia de Ciencias Morales y Políticas de Madrid. El trabajo en las bibliotecas nos ha permitido comprobar las carac-terísticas de la edición y las peculiaridades de los ejemplares.

El rasgo más relevante de esta edición lo constituye, sin duda, su aparato figurativo. Al reseñar de manera específica esta realidad, se tiene en cuenta, tal y como se detalla en las fichas bibliográfico-iconográficas, no solo el hecho de que vaya ilustrada con numerosos grabados, que en este caso son xilografías, sino también la presencia de la imagen en otros puntos de la página, como las iniciales decoradas que aparecen al comienzo de cada libro.

Este aspecto está intrínsecamente relacionado con la reseña de la estructura y la disposición de la página, que constituye uno de los apartados del análisis de las características de la edición que nos revelan aspectos interesantes. El valor de las distinciones tipográficas, desde nuestro punto de vista, revela una jerarquización de la información que se ofrece a través de la composición de cada página, de la que la posición de la imagen es parte integrante. Esta edición, que presenta una composición simple y sin adornos, lleva el texto de la traducción en redonda, marcando con la cursiva las apostillas marginales que cumplen con la labor de señalar en el texto el inicio de los distintos temas en el desarrollo de las historias. Las apostillas que invaden los márgenes juegan visualmente con la colocación de la imagen (figura 5). 


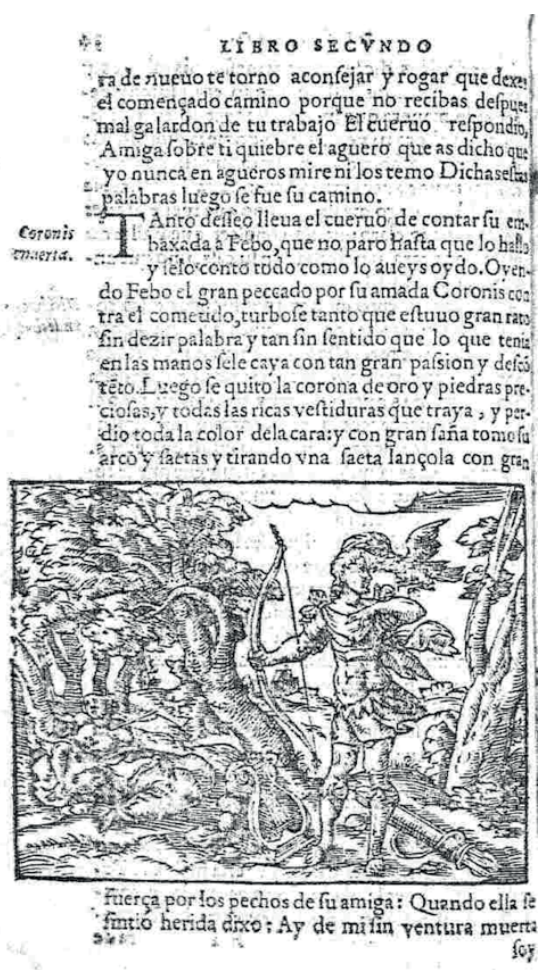

Figura 5.

Vista de página de la edición Metamorfosis.Bustamante.Bellero.Amberes.1595 (fol.34v). Ejemplar digitalizado de la Biblioteca Histórica Marques de Valdecilla (UCM).

Las ilustraciones, que no van enmarcadas, se intercalan en el texto sin una posición fija, ya que se situan indistintamente en la parte inferior, media o superior de la página. Al tratarse de una edición en octavo (la mayor parte de los ejemplares miden en torno a los 16 centímetros), los grabados — que miden seis por ocho centímetros - sobrepasan la caja del texto e invaden el margen, hasta alinearse con las propias apostillas. De este modo, se establece entre ambos, grabados y apostillas, una equiparación en relación con el texto que no parece sencillamente de tipo compositivo, sino que más bien parece que la composición se realiza de esta manera para mostrar a través del equiparamiento visual una semejanza de la tarea de ritmar en el texto y servirle de complementos de la información.

Por lo que se refiere al aparato figurativo, esta edición se imbrica en la tradición de la ilustración profusa del poema, que pretende ofrecer una versión visual de la mayoría de las historias y episodios narrados en el texto. En las Metamorfosis se narran o exponen con mayor o menos detalle unos doscientos cincuenta episodios o historias mitológicas, y la edición de Amberes lleva una serie de ciento setenta y cinco grabados, algunos de los cuales resumen distintos 
momentos de una historia o episodio, mientras que otros desglosan en varios grabados dos o tres momentos de una misma historia.

Este ritmo de representación no es una peculiaridad de esta edición ni responde a la versión que la traducción de Bustamante ofrece del texto ovidiano, ya que los grabados que la ilustran son fidelísimas copias de las planchas que el grabador alemán Virgil Solis (1514-1562) había realizado para acompañar a tres tipos de ediciones distintas del poema. ${ }^{14}$ Sin embargo, los grabados de Solis tampoco respondían a las necesidades de las ediciones que los llevan como aparato figurativo, porque el juego del alemán es, a su vez, una reelaboración de las xilografías originales que hace el famoso grabador francés Bernard Salomon (ca. 1508-1561) para La Métamorphose d'Ovide figurée, una edición especial impresa en Lyon por Jean de Tournes en $1557 .^{15}$

Las copias de la edición española se distinguen con dificultad de sus modelos alemanes, ya que algunas de las estampas de 1595 muestran el monograma $V S$, que constituía la firma de Virgil Solis, lo que hizo pensar en una reutilización de las planchas originales. ${ }^{16}$ Sin embargo, el juego original no solo muestra el monograma del autor en muchas más planchas que el juego que aparece en la edición de Amberes, sino que además incorpora otras marcas de posibles grabadores del taller de Solis, que están ausentes en las planchas de la versión española. De este modo, los grabados que acompañan a la traducción de Bustamante se consideran obra de un autor flamenco anónimo. ${ }^{17} \mathrm{El}$ juego de grabados de este artista desconocido se utiliza el mismo año de 1595 en una edición muy similar en factura y concepción, que se imprime en la misma casa de Pedro Bellero (presentado en esta ocasión bajo su nombre flamenco Peeter Beelaert) y que contiene una traducción flamenca en prosa del poema ovidiano realizada por Johannes Florianus (Jan Blommaerts: 1522-1585). ${ }^{18}$ Como la edición española,

14. El juego completo de los 178 grabados de Solis se utiliza por primera vez en 1563 para acompañar a tres ediciones diferentes de las Metamorfosis impresas por la compañía editorial constituida por Sigmund Feyerabend, Georg Rab (Corvinus) y los herederos de Weigand Han (Gallus) en Fráncfort del Meno: la edición latina de J. Mycillus, la versión latina resumida y alegorizada de J. Spreng, y los Tetrasticha de J. Posthius.

15. Vide supra nota 2.

14. El juego completo de los 178 grabados de Solis se utiliza por primera vez en 1563 para acompañar a tres ediciones diferentes de las Metamorfosis impresas por la compañía editorial constituida por Sigmund Feyerabend, Georg Rab (Corvinus) y los herederos de Weigand Han (Gallus) en Fráncfort del Meno: la edición latina de J. Mycillus, la versión latina resumida y alegorizada de J. Spreng, y los Tetrasticha de J. Posthius.

16. En Díez Platas y Monterroso Montero (1998) y en Díez Platas (2003), antes de haber realizado un estudio exhaustivo de las ediciones y ejemplares, la autora atribuye erroneamente a Virgil Solis las xilografías de la edición de Amberes.

17. Una propuesta ha sido identificarlo con el grabador holandés Christoffel van Sichen el Viejo (Henkel 1926-1927: 94).

18. Se trata de Metamorphosis dat is, die herscheppinghe oft veranderinge, met veel schoone figuren verciert, Antwerpen, typis Andreas Bax ten huyse Peeter Beelaert, 1595: Munich, Bayerische Sta- 
la versión flamenca va acompañada de un juego de ciento setenta y cinco grabados, es decir, tres menos que el juego completo que les había servido de modelo, la serie de ciento setenta y ocho planchas de Solis. ${ }^{19}$

Esta circunstancia aproxima a ambas ediciones, ya que se aprecia que estaban concebidas de manera material como dos versiones de un mismo tipo de producto. Sin embargo, resulta especialmente relevante para mostrar la relación de texto con la imagen un curioso hecho que afecta a las dos. El juego de grabados que acompaña a la edición en español carece, como hemos dicho, de tres grabados: la ilustración del episodio del libro quinto que narra la petrificación de Fineo y sus compañeros en su lucha con Perseo; el grabado que ilustra el episodio del libro sexto en el que se representa el rapto de la ninfa Oritia por Boreas, y el que ilustra el episodio de la transformación de Metra en varias formas, que aparece en el libro octavo. ${ }^{20} \mathrm{La}$ edición flamenca carece igualmente de tres de los grabados de la serie completa, pero las xilografías faltantes no son las mismas que en la edición español, ya que en este caso, no aparece la ilustración para el episodio del libro primero en el que se describe la Edad de oro, ${ }^{21}$ no cuenta tampoco con el grabado del libro segundo que muestra la transformación de las hermanas del infortunado Faetón, las Helíades que acabaron convertidas en árboles, ${ }^{22}$ y no figura el grabado del libro catorce que representa la historia de Pico y Circe. ${ }^{23}$ Sin lugar a dudas, este curioso caso de coincidencia divergente entre las dos traducciones de las Metamorfosis está motivada por el texto. La pieza de Bustamante no es una traducción literal del poema, sino más bien una versión amplificada al estilo de las moralizaciones que trufaron la obra desde bien temprano. Esta circunstancia condiciona la ilustración, si bien no se puede considerar que se busque una total consonancia entre los contenidos expuestos y los representados, ya que, como hemos visto, la serie no está hecha para el texto. ${ }^{24}$

No obstante, esta edición es un caso más de la reutilización constante de las creaciones visuales de los episodios de Ovidio, ya que aunque no se trate de copias exactas, la mayoria de las series dependen de creaciones anteriores y solo en determinados casos nos encontramos con ediciones que presentan un aparato figurativo

atsbibliothek, sign. 923657 A.lat.a. 1228; <http://reader.digitale-sammlungen.de/resolve/display/ bsb10171190.html>.

19. Las xilografías flamencas se vuelven a utilizar en una larga serie de ediciones flamencas que se imprimen en Amberes y Rotterdam a lo largo del siglo xviI, en 1608, 1615, 1619, 1631, 1637 y 1650 (Henkel 1926-1927: 94-95).

20. Las ilustraciones se corresponden con los números 60, 66 y 106 respectivamente de las ediciones alemanas de 1563 .

21. Ilustración número tres de las ediciones alemanas de 1563 y de la edición española de 1595.

22. Ilustración número 23 de las ediciones alemanas de 1563 y de la edición española de 1595 .

23. Ilustración número 176 de las ediciones alemanas y 163 de la edición española.

24. Estas diferencias se hacen evidentes a través del análisis de la influencia de la información de las ilustraciones por encima de la divergente información del texto de la edición. Una muestra muy interesante se encuentra en el trabajo de Sònia Boadas sobre el uso que hizo Lope de Vega de la edición española en la composicion de sus comedias mitológicas. Véase Boadas Cabarrocas (2016). 
creado ad hoc, a las que podríamos denominar «ediciones principes iconográficas». Este sería el caso de la creación de Bernard Salomon, antepasada remota de las planchas de Amberes, a través de las creaciones de Solis. La serie francesa, a la que ya nos hemos referido antes, se realiza para crear una versión figurada del poema que prescinde de la literalidad del texto y pone en primer plano la imagen. Sin embargo, sus copias vuelven a integrarse en el texto del poema, y con ello la imagen prueba su labilidad, pues la serie de Solis se adapta, como vimos, a tres ediciones que ven la luz en 1563 y que son ediciones de distinta índole: una edición del texto latino original con comentarios, ${ }^{25}$ un resumen amplificado con explicaciones de los episodios y alegorías ${ }^{26}$ y una nueva reducción del texto a imagénes acompañadas por glosas o epigramas textuales que pretenden recoger a Ovidio y a la vez verter al latín y al aleman los contenidos de los episodios ${ }^{27}$. La serie constituida migra luego a estas traducciones editadas en Amberes, que presentan una versión extensa en distintas lenguas de la obra mitológica. Sin lugar a dudas, no parece que la adecuación o adaptación fuera mucho más alla de comprobar si el episodio estaba verdaderamente narrado o no en la edición en cuestión, para no alejar del texto la versión figurada e impedir la comprensión ampliada de las historias con la imagen, que probablemente resultaba fundamental posiblemente para los lectores menos versados. En la edición española, que tuvo un gran relieve y una enorme utilización, a pesar de no ser un gran producto editorial ni un libro de valor intrínseco por su edición material, resulta evidente que, gracias al tamaño reducido del libro y del texto y con unos grabados más grandes que la caja del texto, la imagen se enseñorea de la página y se convierte en una importante transmisora de los contenidos narrados.

En la presentación de esta edición en la $B D O$, este aspecto de extraordinaria importancia para la comprensión del valor del libro y su percepción queda, sin embargo, momentáneamente anulado al posibilitar un acceso diferente que modifica la mirada sobre el libro: la contemplación de la galería del imágenes (figura 3). Esta presentación de conjunto de la serie completa y ordenada de los grabados tiene como cometido mostrar la profusión de la ilustración, pero sobre todo de dar

25. Pvb. Ovidii Nasonis Metamorphoseon Libri XV: In singulas quasque Fabulas Argumenta / Ex postrema Iac. Micylli Recognitione. Impressvm Francofvrti: Apvd Georgivm Coruinum, Sigismundum Feierabent, \& haeredes Vuigandi Galli, 1563.

26. METAMORPHOSES OVIDII, ARGVMENTIS QUI//dem soluta oratione, Enarrationibus autem \& Allegoriis Elegiaco uersu accuratissime expositae, summaque diligentia ac studio illustratae, per M. IOHAN. SPRENGIVM AVGVSTAN. una cum uiuis singularum transformationum Iconibus a Virgilio Solis, eximio pictore, delineatis. Frankfurt: G. Coruinus, S. Feyerabent, \& haeredes VVygandi Galli, 1563: <http://ovid.lib.virginia.edu/spreng/OVIM009.html>. 27. IOHAN. POSTHII/ GERMERSHEMII TETRASTI-/CHA IN OVIDII METAM. LIB. XV QVI-/bus accesserunt Vergilij Solis figurae elegantiss./\& iam primum in lucem editae/Schöne Figuren / auß dem fürtrefflichen/Poeten Ouidio / allen Malern / Goldtschmiden /vnd Bildthauwern / zu nutz vnd gutem mit fleiß gerissen durch/Vergilium Solis / vund mit Teutschen Reimen kürtzlich erkläret / dergleichen vormals im Druck nie/außgangen / Durch/Johan. Posthium von Germerßheim/ CVM GRATIA ET PRIVILEGIO CAESAREO/M. D. LXIX: <https://archive. org/stream/iohanposthiigerm00post\#page/n0/mode/2up >. 
cuenta de la estructura del programa iconográfico que supone la versión visual. Gracias a la visión panorámica del conjunto, sin necesidad de hojear el libro página a página, se aprecia, por ejemplo, el número de imágenes asociadas a cada libro y el número de grabados dedicados a ilustrar episodios complejos. De este modo se comprende la estructura de la versión figurada y la cantidad de información visual que se asocia a cada libro.

Asimismo, se constatan las carencias significativas en la estructura figurativa en relación con la estructura de la información textual. En el caso de la ilustración de esta edición, ya hemos indicado que carecía de tres grabados que formaban parte de la serie modelo realizada por Solis. Sin embargo, esta falta solo se puede constatar comparando ambos juegos de grabados. En cambio, resulta más importante poder comprobar la falta de imágenes para ilustrar episodios relevantes y bien conocidos en la tradición ilustrativa, como es el caso de la historia de Aracne, la tejedora lidia que reta a la diosa Minerva y termina metamorfoseada en arańa. Esta historia, que marca el inicio del libro VI en la mayoría de las series figuradas de los episodios del poema, es una pieza esencial desde el punto de vista del texto ovidiano y, por añadidura, es la inspiración de una de las obras artísticas más destacadas de la pintura del Siglo de Oro, Las hilanderas de Velázquez. La interpretación velazqueña, no obstante, no procede ni reproduce ninguno de los modelos visuales que representan el episodio en las ediciones ovidianas. La significativa ausencia, sin embargo, no es sino una carencia heredada del modelo de Solis y, en última instancia, de la serie de Salomon, ya que el grabador francés no realizó ningún grabado para la historia ${ }^{28} \mathrm{y}$, en consecuencia, el fallo del modelo se perpetuó en las copias. La ausencia de una versión figurada del episodio en una edición visualmente tan importante como la española de 1595 fue seguramente significativa desde el punto de vista de la creación artística.

En definitiva, como ya hemos adelantado, es precisamente la herramienta de análisis de la figuración de la $B D O$ que, por una parte, individualiza las imágenes extrayéndolas de su contexto en el libro y, por otra, las reúne para mostrarlas en una galería virtual, lo que permite un acercamiento distinto al libro ilustrado, facilitando la investigación de la vida de los episodios representados para comprender, entre otras cosas, la razón por la que una serie de historias tuvieron una relevancia menor en el conocimiento y en la difusión por medios visuales. En el caso de la edición de Amberes, nos permite contemplar desde la imagen la versión española del influjo de la Aetas Metamorphoseos.

28. La carencia se subsana en la versión italiana de la edición de Salomon que realiza Gabriello Simeoni y que ve la luz en Lyon en 1559. La nueva edición amplía y corrige la edición francesa incorporando ocho grabados más entre los que se cuenta una xilografía para la historia de Aracne (ilustración número 76, p. 88). Una copia digitalizada se puede consultar en <http://gallica.bnf.fr/ ark:/12148/bpt6k72174q/f2.planchecontact>. 


\section{Bibliografía}

Alpers, Svetlana, The Decoration of the Torre de la Parada, Corpus Rubenianum Ludwig Burchard, Parte IX, Bruselas, Arcade Press, 1971.

Boadas Cabarrocas, Sònia, "Los grabados de Virgil Solis: una fuente iconográfica para las comedias mitológicas de Lope de Vega», Hispanic review, 4 (2016), 427-457.

Carrasco Rejja, Leticia, «La traducción de las Metamorfosis de Ovidio por Jorge de Bustamante», Humanismo y pervivencia del mundo clásico: Homenaje al profesor Luis Gil, vol. II, Cádiz, Servicio de publicaciones de la Universidad de Cádiz, 1997, 987-994.

Díez Platas, Fátima, «Researching Illustrated Books in Art History: A Brief History of the Biblioteca Digital Ovidiana Project», Dynamic Research Support for Academic Libraries, ed. Starr Hoffman, Londres, Facet Publishing, 2016, 21-32.

—, «Tres maneras de ilustrar a Ovidio: una aproximación al estudio iconográfico de las Metamorfosis figuradas del XVI», eds. Ma C. Folgar de la Calle, A. E. Goy Diz y J. M. López Vázquez, Memoria Artis. Studia in memoriam Ma Dolores Vila Jato, Santiago de Compostela, Xunta de Galicia, vol. I, 2003, 247-267.

Díez Platas, Fátima y Meilán Jácome, Patricia, «De texto con imágenes a imágenes con texto: la confusa transformación de las Metamorfosis ilustradas en la primera mitad del s. XVI», Omnia Mvtantur. Canvi, transformació $i$ pervivència en la cultura clàssica, en les seves llengues i en el seu llegat, eds. E. Borrell Vidal y O. de la Cruz Palma, Barcelona, Edicions de la Universitat de Barcelona, vol. II, 2016, 275-283.

Díez Platas, Fátima y Monterroso Montero, Juan Manuel, «Mitología para poderosos: las Metamorfosis de Ovidio. Tres ediciones ilustradas del siglo XVI en la Biblioteca Xeral de Santiago", Semata. Ciencias Socials e Humanidades, 10 (1998), 451-472.

Díez Platas, Fátima et al., «Mitos de libro: la ilustración de las Metamorfosis de Ovidio en las ediciones españolas del siglo XVI», Imagen y Cultura. La Interpretación de las Imágenes como Historia Cultural, eds. R. García Mahíques y V. F. Zuriaga Senent, Biblioteca Valenciana, Valencia, Gandía, Universitat Internacional de Gandía, vol. I, 2008, 549-562.

Fernández Valladares, Mercedes, «Biblioiconografía y literatura popular impresa: la ilustración de los pliegos sueltos burgaleses (o de babuines y estampas celestinescas)", eHumanista, 21 (2012), 87-131.

Henkel, Max Ditmar, «Illustrierte Ausgaben von Ovids Metamorphosen im XV., XVI. und XVII. Jahrhundert», Vorträge der Bibliothek Warburg, Berlín/ Leipzig, 1926-1927, 58-144. 